\title{
Isolation and molecular characterization of type I and type II feline coronavirus in Malaysia
}

\author{
Alazawy Amer ${ }^{1,2}$, Arshad Siti Suri ${ }^{*}$, Omar Abdul Rahman ${ }^{1}$, Hair Bejo Mohd ${ }^{1}$, Bande Faruku', Sharif Saeed ${ }^{1}$ \\ and Tengku Ibrahim Tengku Azmi ${ }^{3}$
}

\begin{abstract}
Background: Feline infectious peritonitis virus (FIPV) and feline enteric coronavirus (FECV) are two important coronaviruses of domestic cat worldwide. Although FCoV is prevalent among cats; the fastidious nature of type I FCoV to grow on cell culture has limited further studies on tissue tropism and pathogenesis of FCoV. While several studies reported serological evidence for FCoV in Malaysia, neither the circulating FCoV isolated nor its biotypes determined. This study for the first time, describes the isolation and biotypes determination of type I and type II FCoV from naturally infected cats in Malaysia.

Findings: Of the total number of cats sampled, 95\% (40/42) were RT-PCR positive for FCoV. Inoculation of clinical samples into Crandell feline kidney cells (CrFK), and Feline catus whole fetus-4 cells (Fcwf-4), show cytopathic effect (CPE) characterized by syncytial cells formation and later cell detachment. Differentiation of FCoV biotypes using RT-PCR assay revealed that, $97.5 \%$ and $2.5 \%$ of local isolates were type I and type II FCoV, respectively. These isolates had high sequence homology and phylogenetic similarity with several FCoV isolates from Europe, South East Asia and USA.
\end{abstract}

Conclusions: This study reported the successful isolation of local type I and type II FCoV evident with formation of cytopathic effects in two types of cell cultures namely the CrFK and Fcwf-4, where the later cells being more permissive. However, the RT-PCR assay is more sensitive in detecting the antigen in suspected samples as compared to virus isolation in cell culture. The present study indicated that type I FCoV is more prevalent among cats in Malaysia.

Keyword: FCoV, FIPV, CrFK, Fcwf-4, S-gene, Phylogenetics, Cats, Malaysia

\section{Findings}

Feline coronavirus (FCoV) is an enveloped RNA virus belonging to Coronaviridae. The disease is prevalent especially in catteries and multiple-cat household [1]. FCoV consist of two biotypes; Feline infectious peritonitis (FIPV) which is highly fatal and caused immune mediated complex, and feline enteric coronavirus (FECV) which caused from asymptomatic infection to severe enteritis $[1,2]$.

Two types of FCoV could be distinguished based on serology and sequence analysis. Type I FCoV is wholly feline-associated and prevalent in natural cases of coronavirus infections but it poorly proliferates in cell

\footnotetext{
* Correspondence: suri@putra.upm.edu.my

${ }^{1}$ Department of Veterinary Pathology and Microbiology, Faculty of Veterinary Medicine, Universiti Putra Malaysia, UPM Serdang, Selangor 43400, Malaysia Full list of author information is available at the end of the article
}

culture. On the other hand, type II FCoV is less common but grows in different cell lines such as Fcwf- 4 and CrFK cells $[3,4]$.

Although evidence of FIP have been reported among cat population in Malaysia [5,6], the circulating FCoV virus neither isolated nor characterized. Thus, the objectives of this study are to isolate and determine the FCoV biotypes occurring in Malaysia.

Of the 42 RNA samples used in this study, 40 samples (95\%) were positive and 2 samples (5\%) were negative for FCoV following RT-PCR assay. Of these, RT-PCR positive samples, 95\% (40/42) and 73.8\% (31/42) were able to adapt and multiply in Fcwf- 4 and CrFK cell cultures, respectively. Two samples which were positive with RT-PCR assay were found not to grow in cell culture. The entire 40 tissue culture adapted virus were used in the subsequent studies. 
Upon virus inoculation, infected CrFK cells showed initial CPE at passage two with moderate to diffuse CPE at 4-5 days post inoculation (PI). The appearance of $\mathrm{CPE}$ became rapid during second and third passages. As the virus propagation reaches the fifth passages; the onset of CPE appeared within 24-48 hours PI. Complete CPE (> 80\%) was noticed 48-72 hours PI (Figure 1). On the other hand, infected Fcwf-4 cells showed initial CPE following first passage, with some samples at second passages. The initial CPE was recorded at 2-3 days PI. As the virus passages reach the third passages, the onset of CPE appeared within 24 hours PI and completed within 36-48 hours PI (Figure 2).

Both infected CrFK and Fcwf-4 cells showed similar morphological changes characterized by increased opacity and refractile of the infected cells. Infected cells become rounded, granular and clumped forming syncytial cells which increased in size and number as the incubation period extended. Syncytial cells were observed to contain between 20-30 nuclei per cell at 36-48 hours PI, although 8-10 nuclei per cell was most common (Figure 3). Morphological changes observed in CrFK and Fcwf-4 following infection with FCoV isolates were comparable to reference FIPV-79-1146. Both control uninfected cells remained normal.

Indirect immunofluorescent antibody test (IIF) on infected cells showed viral antigens were present in the cytoplasm, where the earliest signals appeared as fine to coarse immunofluorescent granules in the perinuclear region of the infected cells at 6 hours PI (Figure 4).

Differentiation of FCoV using specific primer sets for type I (fecv1b) and type II FCoV (fecv2b) yielded an expected amplification product of $275 \mathrm{bp}$ and $232 \mathrm{bp}$ denoting to type I FCoV ( $\mathrm{n}=39 / 40)$ and type II FCoV $(n=1 / 40)$, respectively ( data not shown). A total of 13 selected RT-PCR products samples, each from type I $\left(\mathrm{n}_{1}=12\right)$ and type II $\left(\mathrm{n}_{2}=1\right)$ local FCoV were sequenced for compared with reference strains and subjected for phylogenetic analysis.

The findings from phylogenetic analysis of local FCoV further support their biotyping where majority of local FCoVs $(n=12)$ closely branched together with type I reference FCoV and only one sample; UPM8Ca/08 was found to cluster with type II FCoV (Figure 5). The nucleotide sequences and accession numbers of isolates derived from this study have been deposited in the NCBI GenBank database (Table 1).

Comparison amongst local FCoV type I sequences revealed high degree of sequence homology, ranging from 93.2-99.5\%. However, this similarity decreases to $90 \%$ when compared with the reference isolates. In contrast, type II FCoV isolates (UPM8Ca/08) only shows sequence identity ranging from $77.6-79 \%$ when compared with reference isolates. Malaysian FCoV type I isolates were phylogenetically closer to $\mathrm{FCoV}$ isolates from America, South East Asia, and Europe while UPM8Ca/ 08 which is the only identified type II isolates, was closer to FIPV 79-1146 and FIPV DF2 reference isolates originating from USA (Figure 5).

In this study, both RT-PCR and virus isolation were employed to detect the presence of FCoV from naturally infected domestic cats. The FCoV detection rate (95\%) observed in this study is comparably higher than reported by Herrewegh et al. [7].

Based on partial S-gene sequence, the circulating virus in Malaysia was found to be predominately of type I FCoV (39/40). High incidence of type I FCoV (97.5\%) in comparison to type II FCoV (2.5\%) is in agreement with other findings reported in countries like Japan, Australia and Korea [8-10]. Similarly, the sequence homology observed among local FCoV isolates were in agreement with Lin et al. [11].

Comparing for virus adaptation in two cell lines revealed that Fcwf-4 was more permissive to local FCoV

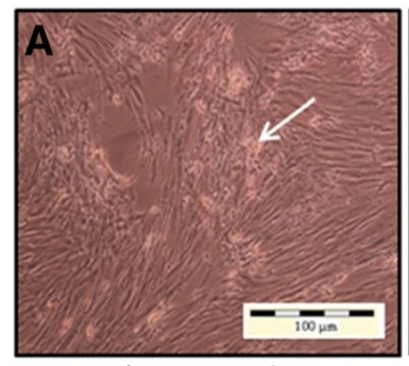

Isolate UPM11C/08

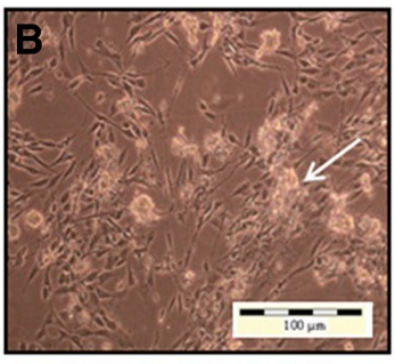

Reference FIPV-79-1146

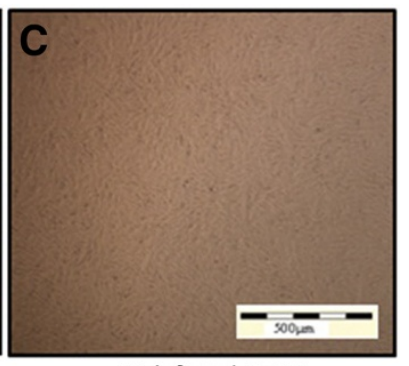

Uninfected CrFK

Figure 1 CrFK-4 cell cultures showing cytopathic changes following infection with reference and local FCoV isolate UPM 11C/08.

Morphology of cells infected with local FCoV UPM 11C/08 isolate at passage 3 (A). where the initial CPE was observed at passage 2. At fifth viral passages, complete CPE occurred within 48-72hours PI. Morphology of cells infected with reference FIPV-79-1146 strain (B). Infected cells show CPE characterized by cells rounding, clumped and detachment (arrows). Note that the changes in cells infected with UPM11C/08 are comparable to reference strain. Control uninfected cells remained normal (C). Unstained. 


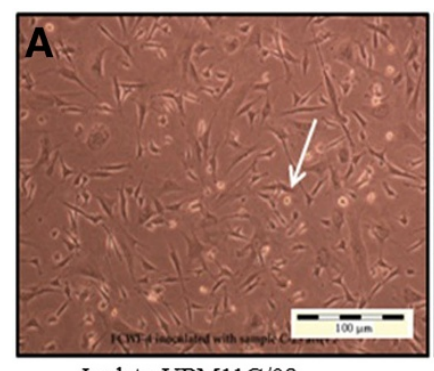

Isolate UPM11C/08

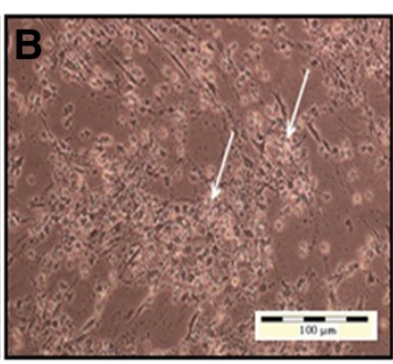

Reference FIPV-79-1146

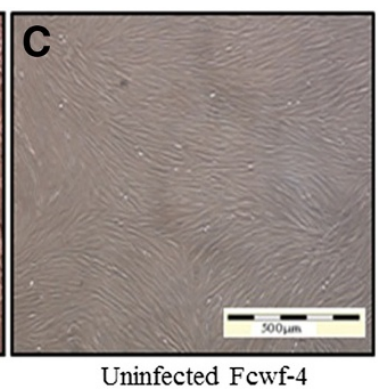

Figure 2 Fcwf-4 cell cultures showing cytopathic changes following infection with reference and local FCoV isolate UPM 11C/08.

Morphology of cells infected with local FCoV UPM 11C/08 isolate at passage 3 (A). where the initial CPE was observed at passage 1. At third viral passages, complete CPE occurred within 24 hours PI. Morphology of cells infected with reference FIPV-79-1146 strain. (B). The infected cells show CPE characterized by cells rounding, clumped and detachment (arrows). Note that the changes in cells infected with UPM11C/08 are comparable to reference strain. Control uninfected cells remained normal (C). Unstained.

replication. Thus, all local FCoV type I isolates (39/39) were able to adapt and grow in Fcwf-4 cells as compared to only $77 \%$ (30/39) samples that grow on CrFK cells (data not shown). This finding further support the predilection of type I FCoV towards macrophages $[4,12]$. Replication of the virus is restricted in the cytoplasm of the infected cells as indicated by the presence of the fluorescent signals with the production of virus particle typical of coronavirus (13).

In conclusion, this study described the isolation of $\mathrm{FCoV}$ in feline cell culture from domestic cats in Malaysia. The isolates replicate in CrFK and Fcwf-4 cell cultures with the formation of CPE comparable to reference strain. Phylogenetic analyses show that majority of the local FCoV isolates belongs to type I and rarely of type II biotypes. Additionally, the study revealed that, Malaysia FCoV s is phylogenetically related with isolates from South East Asia, USA and UK, signifying possible common ancestral origin.

\section{Material and methods}

Ascitic fluid sample $(n=27)$ and postmortem tissues $(\mathrm{n}=15)$ were collected from 42 clinically ill client-owned presented at University Veterinary Hospital, Universiti Putra Malaysia (UVH -UPM) during 4-year period (2007-2010). The sampled cats comprises of 28 male and 14 females with age range from 6 month to 5 years. All cats came from neibouring areas within Klang valley and had no previous history of vaccination against FCoV as FIP vaccination is not a common practice in most clinics. Samples were consecutively designated as FCoV UPM1C/07 to UPM42C/10. The samples were processed and inoculated onto the CrFK (ATCC ${ }^{\circledR}$; CCL-94) and Fcwf-4 (ATCC; CRL-2787) as described previously [13].

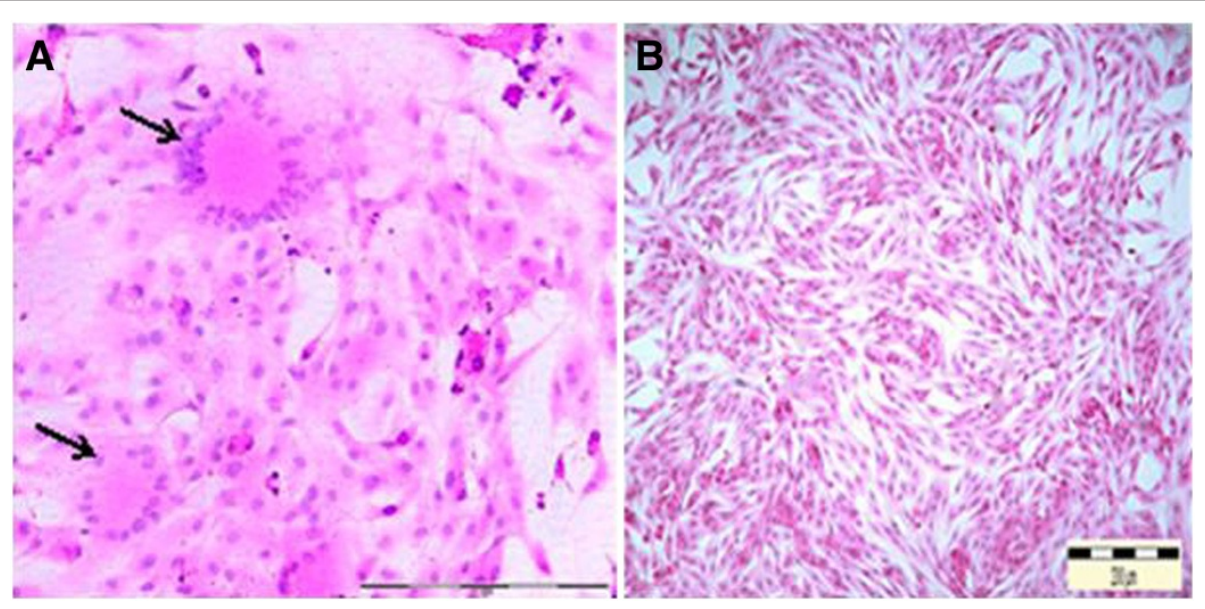

Figure 3 Syncytial cells formation following infection of Fcwf-4 cell culture with FCoV UPM 11C/08 isolate. Infected cells show loss of plasma membrane and nuclear aggregation, resulting in formation of syncytial cells containing more than 20 nuclei (arrows), 36 hours Pl. 20x Mag. Scale bar, $100 \mu \mathrm{m}$. Normal uninfected Fcwf-4 cell culture at 72 hours. H\&E staining (A). Cells appeared as spindle to stellate morphology and regularly arranged. 10x Mag. Scale bar, $200 \mu \mathrm{m}$ (B). 

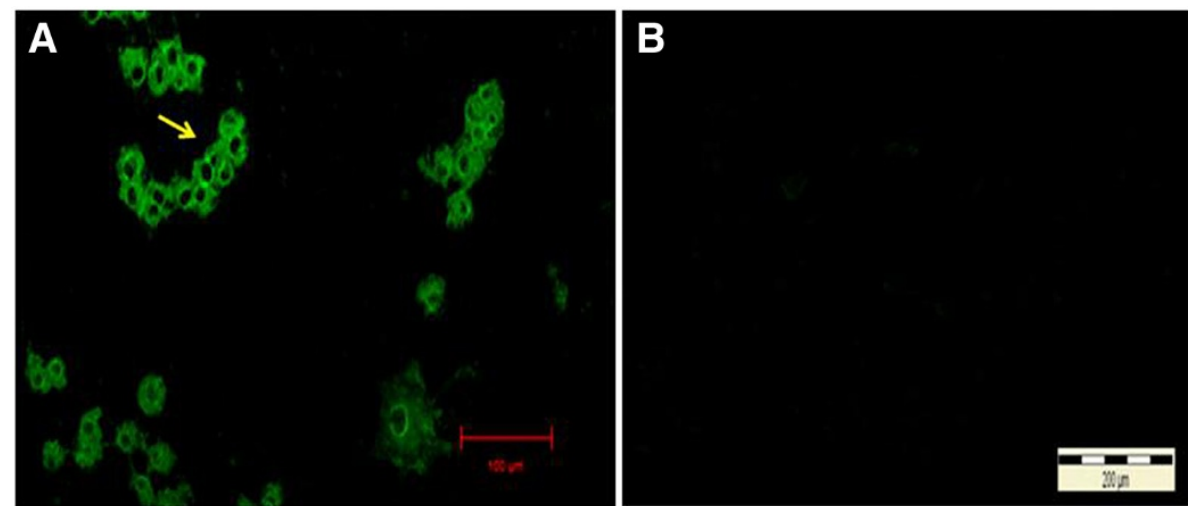

Figure 4 Immunofluorescent antibodies staining of infected CrFK cells following infection with local FCoV UPM11C/08 isolate. The fluorescence signal appeared as granules covering areas within the cytoplasm at 24 hours PI (arrow). No signal is present in the nucleus. 100x

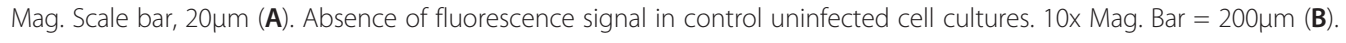

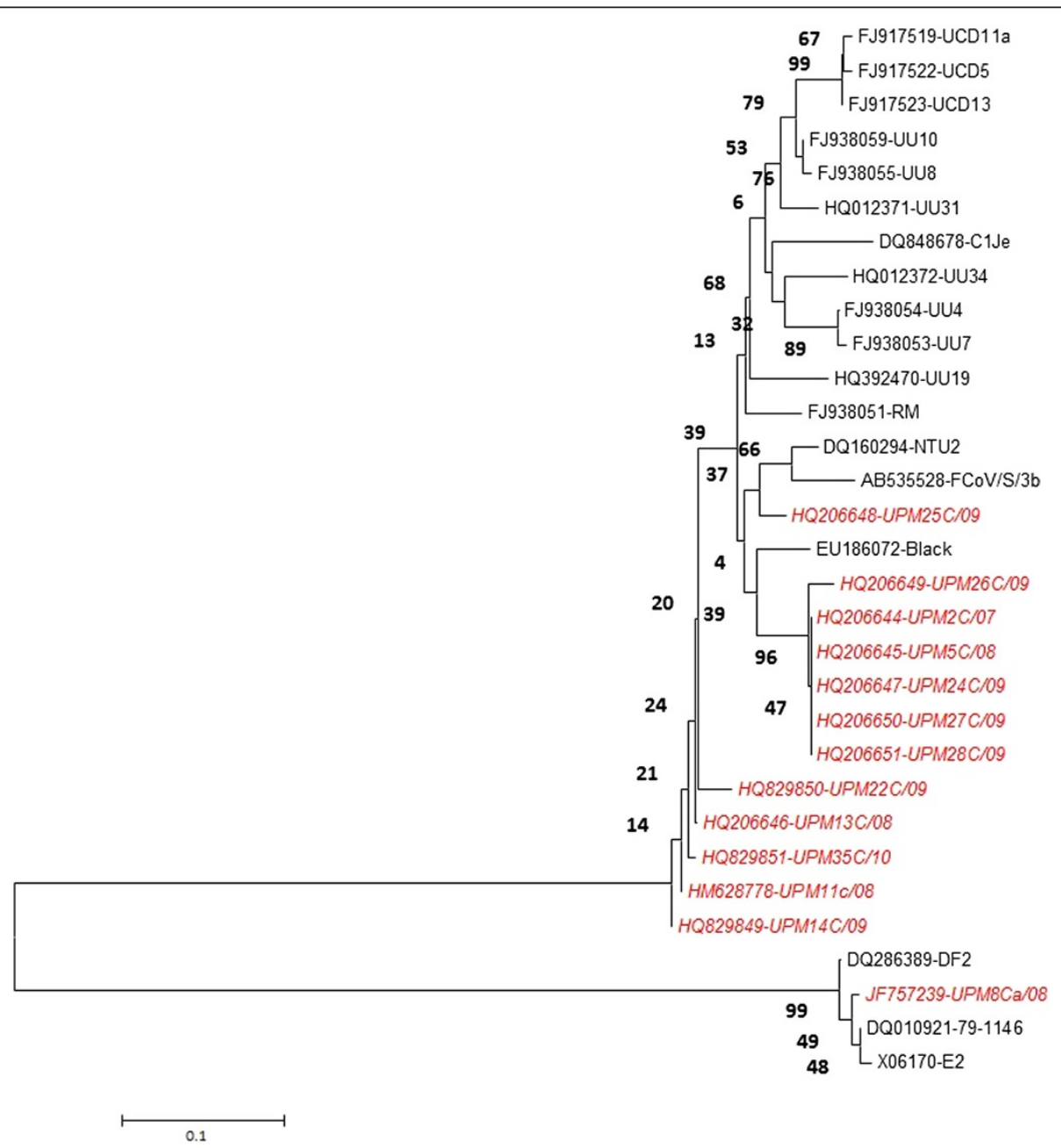

Figure 5 Phylogenetic tree depicting relationships between Malaysian FCoV and reference FCoV isolates based on partial S gene sequence. The tree was generated using MEGA5 program. The tree reliability was calculated using 1000 bootstrapped replicates. Malaysian FCoVs are indicated in red italic. 
Table 1 List of sequences used in the phylogenetic analysis of Malaysian FCOVs isolates

\begin{tabular}{|c|c|c|c|}
\hline Isolate/ Strain & Accession No. & Country & Nucleotide position used \\
\hline UPM2C/07 & HQ206644 & Malaysia & $1-224$ \\
\hline UPM5C/08 & HQ206645 & Malaysia & $1-224$ \\
\hline UPM11C/08 & HM628778 & Malaysia & $1-221$ \\
\hline UPM13C/08 & HQ206646 & Malaysia & $1-224$ \\
\hline UPM8Ca/08 & JF757239 & Malaysia & $1-199$ \\
\hline UPM14C/09 & HQ829849 & Malaysia & $1-224$ \\
\hline UPM22C/09 & HQ829850 & Malaysia & $1-224$ \\
\hline UPM24C/09 & HQ206647 & Malaysia & $1-224$ \\
\hline UPM25C/09 & HQ206648 & Malaysia & $1-224$ \\
\hline UPM26C/09 & HQ206649 & Malaysia & $1-221$ \\
\hline UPM27C/09 & HQ206650 & Malaysia & $1-224$ \\
\hline UPM28C/09 & HQ206651 & Malaysia & $1-224$ \\
\hline UPM35C/10 & HQ829851 & Malaysia & $1-224$ \\
\hline FCoV Black & EU186072 & USA & $24623-24846$ \\
\hline FCoV UU19 & HQ392470 & Netherlands & $24610-24830$ \\
\hline FCoV RM & FJ938051 & USA & $24572-24792$ \\
\hline FCoV UU31 & HQ012371 & Netherlands & $24613-24833$ \\
\hline FCoV UU10 & FJ938059 & Netherlands & $24626-24849$ \\
\hline FIPV UCD11a & FJ917519 & USA & $4290-4513$ \\
\hline FCoV UU8 & FJ938055 & Netherlands & 24613-24836 \\
\hline FCoV UU4 & FJ938054 & Netherlands & $24620-24843$ \\
\hline FCoV UU7 & FJ938053 & Netherlands & $24620-24843$ \\
\hline FCoV/NTU2 & DQ160294 & Taiwan & $4294-4517$ \\
\hline FCoV UU34 & HQ012372 & Netherlands & $24562-24785$ \\
\hline $\mathrm{FCoV} / \mathrm{S} / 3 \mathrm{~b}$ & AB535528 & Japan & $3568-3791$ \\
\hline FIPV UCD13 & FJ917523 & USA & $4316-4539$ \\
\hline FCoV C1Je & DQ848678 & UK & $24616-24839$ \\
\hline FECV UCD5 & FJ917522 & USA & $4316-4539$ \\
\hline FIPV 79-1146 & DQ010921 & USA & $24507-24691$ \\
\hline FIPV DF2 & DQ286389 & USA & $24737-24921$ \\
\hline FIPVE2 & X06170 & Italy & $4371-4500$ \\
\hline
\end{tabular}

Uninfected CrFK and Fcwf-4 cells were used as negative control. The study was approved by Institution's Animal Care and Use Committee, UPM (AUP No. 08R47).

Haematoxylin and eosin (H\&E) staining of cell cultures was carried as described by Hsiung [14]. On the other hand, indirect immunofluorescent (IIF) test using polyclonal antibodies against FIPV 79-1146 virus was performed according to the method of Evermann et al. [15].

Viral RNA was extracted from infected cell cultures or Ascites fluid using Trizol Reagent (Invitrogen, USA) according to manufacturer's instructions. RT-PCR was performed using Access RT-PCR system (Promega, USA) [6] with previously described primers p205 and p211 [16]. Positive samples were further differentiated into type I and type II FCoV using biotypes specific oligonucleotide primers targeting S-gene region [17]. All primers were synthesized by First Base Laboratories Sdn Bhd, Selangor, Malaysia.

To gain insight on the genetic relatedness of Malaysian FCoV isolates, the partial S-gene sequences of randomly selected RT-PCR positive samples $(n=13)$ were sequenced using the ABI BigDye ${ }^{\circledR}$ Terminator v3.1 cycle sequencing ready reaction kit (Applied Bioscience). Nucleotide sequences were compared with the corresponding reference $\mathrm{FCoV}$ isolates using BLAST software available in NCBI database. Phylogenetic tree was constructed with MEGA5 software using Neighbor Joining tree method. 
The reliability of the phylogenetic trees was calculated using 1000 bootstrap [18] (Figure 5).

\section{Abbreviations}

FCoV: Feline coronavirus virus; RT-PCR: Reverse transcriptase polymerase chain reaction; RNA: Ribonucleic acid; LTR: Long terminal repeat; NCBI: National Centre for Biotechnology Information; UPM: Universiti Putra Malaysia.

\section{Competing interests}

The authors declare that they have no competing interest.

\section{Authors' contributions}

AA: carried out the study and prepared the manuscript; SSA: Conceived the study, edited the manuscript and approved final copy for submission; OAR and $M H B$, participated in the study design and proof-read the manuscript; FB: carried out phylogenetic analysis, participated in manuscript drafting, proof-reading and submissions. SS: Optimized RT-PCR method for FCoV screening. All authors have read and approved final manuscript.

\section{Acknowledgements}

The authors would like to extend their appreciations to the UVH-UPM for providing the samples and to Dr. Viviane Benetka, University of Veterinary Medicine, Vienna, Austria, for kindly providing the reference FCoV RNA samples. This work was funded by the Ministry of Science, Technology and Innovation (MOSTI) Malaysia, project number 02-01-04-SF0485: Development of rapid test for diagnosis of feline coronavirus.

\section{Author details}

'Department of Veterinary Pathology and Microbiology, Faculty of Veterinary Medicine, Universiti Putra Malaysia, UPM Serdang, Selangor 43400, Malaysia. ${ }_{2}^{2}$ Iraq, Ministry of Higher Education \& Scientific Research, College of Veterinary Medicine, University of Diyala, Diyala, Iraq. ${ }^{3}$ Department of Veterinary Preclinical Sciences, Faculty of Veterinary Medicine, Universiti Putra Malaysia, UPM Serdang, Selangor 43400, Malaysia.

Received: 5 April 2012 Accepted: 15 November 2012 Published: 21 November 2012

\section{References}

1. Addie DD, Jarrett JO: A study of naturally occurring feline coronavirus infection in kittens. Vet Rec 1992, 130:133-137.

2. Boyle JF, Pedersen NC, Evermann JF, McKeirnan AJ, Ott RL, Black JW: Plaque assay, polypeptide composition and immunochemistry of feline infectious peritonitis virus and feline enteric coronavirus isolates. Adv Exp Med Biol 1984, 173:133-147.

3. Motokawa K, Hohdatsu T, Aizawa C, Koyama H, Hashimoto H: Molecular cloning and sequence determination of the peplomer protein gene of feline infectious peritonitis virus type I. Arch Virol 1995, 140:469-480.

4. Pedersen NC: A review of feline infectious peritonitis virus infection: 1963-2008. J Feline Med Surg 2009, 11:225-258.

5. Arshad SS, Lee WW, Hassan L, Kamarudin AIM, Siti-Farawahida AW, Cheng NABY: Serological survey of catteries for cats infected with feline coronavirus. J Vet Malaysia 2004, 17:19-22.

6. Sharif S, Arshad SS, Hair-Bejo M, Omar AR, Zeenathul NA, Fong LS: Descriptive distribution and phylogenetic analysis of feline infectious peritonitis virus isolates of Malaysia. Acta Vet Scandinavica 2010, 52:1-7.

7. Herrewegh AAPM, Smeenk I, Horzinek MC, Rottier PJM, de Groot RJ: Feline coronavirus type II strains 79-1683 and 79-1146 originate from a double recombination between feline coronavirus type $I$ and canine coronavirus. J Virol 1998, 72:4508-4520.

8. Hohdatsu T, Okada S, Ishizuka Y, Yamada H, Koyama H: The prevalence of types I and II feline coronavirus infections in cats. J Vet Med Sci 1992, 54:557-562.

9. Benetka V, Kubber-Heiss A, Kolodziejek J, Nowotny N, Hofmann-Parisot M, Mostl K: Prevalence of feline coronavirus types I and II in cats with histopathologically verified feline infectious peritonitis. Vet Microbio 2004, 99:31-42.

10. An DJ, Jeoung HY, Jeong W, Park JY, Lee MH, Park BK: Prevalence of Korean cats with natural feline coronavirus infections. Virol J 2011, 8:455.
11. Lin CN, Su BL, Wang CH, Hsieh MW, Chueh TJ, Chueh LL: Genetic diversity and correlation with feline infectious peritonitis of feline coronavirus type I and II: a 5-year study in Taiwan. Vet Microbiol 2009, 136:233-239.

12. Pedersen NC: An overview of feline enteric coronavirus and infectious peritonitis virus infections. Feline Pract 1995, 23:7-20.

13. Alazawy A, Arshad SS, Bejo MH, Omar AR, Tengku Ibrahim TA, Sharif S, Bande F, Awang-Isa K: Ultrastructure of Felis catus whole fetus (Fcwf-4) cell culture following infection with feline coronavirus. J Electron Microsc 2011, 60:275-282.

14. Hsiung GD: Diagnostic virology- an illustrated handbook. New Haven and London: Yale University Press; 1973.

15. Evermann JF, Heeney JL, McKeirnan AJ, O'Brien SJ: Comparative features of a coronavirus isolated from a cheetah with feline infectious peritonitis. Virus Res 1989, 13:15-27.

16. Herrewegh AAPM, De Groot R, Cepica A, Egberink HF, Horzinek MC, Rottier $P$ : Detection of feline coronavirus RNA in feces, tissues, and body fluids of naturally infected cats by reverse transcriptase PCR. J Clin Microbio 1995, 33:684-695.

17. Posch A, Posch U, Kubber-Heiss A, Seiser M, Moestl K: Differentiation of feline coronaviruses type I and II strains by RT-PCR. In Proceedings of the WSAVA World veterinary congress. Lyon; 1999.

18. Felsenstein J: Confidence limits on phylogenies: an approach using the bootstrap. Evolution 1985, 39:783-791.

doi:10.1186/1743-422X-9-278

Cite this article as: Amer et al:: Isolation and molecular characterization of type I and type II feline coronavirus in Malaysia. Virology Journal 2012 9:278.

\section{Submit your next manuscript to BioMed Central and take full advantage of:}

- Convenient online submission

- Thorough peer review

- No space constraints or color figure charges

- Immediate publication on acceptance

- Inclusion in PubMed, CAS, Scopus and Google Scholar

- Research which is freely available for redistribution

Submit your manuscript at www.biomedcentral.com/submit
C Biomed Central 